\title{
The Characteristics of Preschool Mathematics Education in the United Kingdom and Its Inspiration
}

\author{
Wanchun Wang* \\ Preschool Education Department, Shaanxi Xueqian Normal University, Xi'an Shaanxi, China \\ ${ }^{*}$ Corresponding author. Email: 544405974@qq.com
}

\begin{abstract}
Mathematics education is an important part of the preschool children's all-round development, occupying the important status in the teaching activities of the kindergarten. Young children can develop mathematical logic thinking ability, and accumulate mathematical experience, form good learning quality. At the same time mathematics education also can help children establish varied and vivid appearance, be helpful for future absorption, expand scientific knowledge and have provided a strong knowledge protection for the infant's creation, invention ability. The British government attaches great importance to preschool education, especially in mathematics education. Based on the British Curriculum Guidance for the Foundation Stage, this paper generally introduced the curriculum provision of the preschool education in the UK. Connecticut preschool Curriculum Standards has significant features. Through learning the experience of preschool mathematics education in the UK, our country's preschool mathematics education should be combined with our own situation, such as, highlighting the cultivation of abilities in preschool mathematics, emphasizing curriculum contents close to life; expanding various education forms and approaches. In this way, children's mathematics abilities and comprehensive development can be greatly improved. According to the current situation of preschool education in China, formulating kindergarten mathematics curriculum standards have been advanced. And by examining the British educators' thoughts on preschool education, this paper studied the theoretical support for the curriculum provision, thus supplying some corresponding reference and enlightenment for the practice of Chinese preschool education.
\end{abstract}

Keywords: The UK, Preschool mathematics education, Kindergarten curriculum.

\section{INTRODUCTION}

The outline of the national medium and long-term education reform and development plan (2010-2020) clearly states that the preschool education will be basically universal by 2020 . Preschool education is of great significance to children's physical and mental health, habit formation and intellectual development [1]. With the rapid development of science and technology, people pay more and more attention to mathematics education, and mathematics education has become the priority of education development in many national kindergartens. Mathematics is a core part of young children's cognitive development, and mathematics learning level affects children's future learning ability to some extent. Preschool mathematics education is not only the foundation for cultivating children's scientific literacy and cognition of objective things, but also the premise and condition for future learning. The preschool mathematics involves simple number concept, preliminary time, and space concept and so on. The British government attaches great importance to preschool education, and pays special attention to cultivating children's mathematical application ability in the aspect of mathematics education. It is of great value and guiding significance to explore the general trends and features of education in British preschool mathematics curriculum, which is setting for practical mathematics activities of Chinese kindergartens.

\section{AN OVERVIEW OF THE CURRICULUM OF PRESCHOOL MATHEMATICS IN THE UK}

The construction of kindergarten mathematics curriculum standard is helpful to enrich the theory of kindergarten mathematics curriculum and has guiding significance for kindergarten mathematics education 
activities. British preschool mathematics education mainly targets children aged 3-5 years [2]. Since the end of 1990s, the UK government has been constantly reforming and developing the preschool education curriculum to solve the long-standing problem that is, lacking a national standard for preschool education quality of service.

In 1995, the British school curriculum and assessment authority published the education development goal for children aged four. In 2000, the British government issued for 3-5 years old children's Curriculum Guidance for the Foundation Stage, mathematics, as the basic education stage of the course, is one of the major areas of the curriculum content of "mathematics", which mainly involves count, graphics, time, space, measure. Such content promote children to better comprehend the logarithm, size, design, shape, space [3]. In 2003, The British government issued The Learning Country: The Foundation Phase - 3 to 7 years, The file will be "The Development of Mathematics." as one of the seven areas of course content, "The Development of Mathematics and Learning" refers to the use and application of four parts, such as mathematics, computing and processing data, measurement, shape and space and so on [4]. In 2005, The British government promulgated "The Early Years Foundation Stage", which regards "problem solving, reasoning and calculation ability" as the main goal of children's mathematical learning and development [2]. In 2012, the Statutory Framework for the Early Years Foundation Stage issued by the British government points out that the kindergarten curriculum goals include communication and language, personal, social and emotional development, understanding of the world, innovative thinking development. "Mathematics" requires teachers to provide opportunities for the math skills development of preschool children, and children need to understand and use mathematics, computing digital addition, subtraction, to describe the shape, space, and length [5]. In 2013, the department of education issued another Document named "The National Curriculum in England - Framework Document", which guided the reform of basic education curriculum. It stipulated that mathematics was the core subject of every age [6]. The development of children's mathematical numeracy is still an important goal of the mathematics curriculum, which is three levels, that is, smooth apply mathematical knowledge, mathematical reasoning, and apply mathematical knowledge to solve complex problems. Cultivating children's mathematical literacy is not only a matter of mathematics teachers, but also related to teachers of other disciplines [7].

The above series of policies on preschool education courses have been constantly promulgated and implemented, which has enabled UK preschool education to achieve steady development and increasingly improve the quality of preschool education.
Throughout the past decade, the UK has revised the mathematics curriculum standards for many times, but all of them have maintained a certain continuity and stability, integrating the goals, contents, learning segments, evaluation standards, etc., and then deepening the idea of mathematics application.

\section{THE CHARACTERISTICS OF PRESCHOOL MATHEMATICS EDUCATION IN THE UK}

The British preschool mathematics curriculum is set on the basis of drawing on the child development theory and game theory of Piaget, Bruner, Vygotsky and others and fully following the law of children's cognitive development. The features of British preschool mathematics education can be summarized as the following four aspects.

\subsection{Attention is Paid to the Development of Preschool Children's Ability to Apply Mathematics}

The national curriculum council demands that all schools focus on math. It is required to acquire knowledge, increase skills and strengthen understanding while putting the ability of problem-solving and material use into practice. The course problems or other subject questions can be put forward while using mathematics to solve real life problems. In this way, the internal principles and laws of mathematics are explored [8]. The Learning Country: The Foundation Phase - 3 to 7 years pointed out that the basic stage of mathematics education requires children to be able to solve problems, communicate mathematical experience and carry out mathematical reasoning, and develop the ability to use and use mathematics through practical activities [9].

British preschool mathematics education aims to enable children to apply mathematics to real life and find mathematical problems from real life, so as to strengthen the application awareness of mathematics and improve the application ability of mathematics. At the same time, the British government further emphasized that preschool teachers should scientifically allocate the knowledge content fields of mathematics (calculation and algebra, geometry and measurement, data analysis and probability, etc.) and process fields (problem solving, reasoning and evidence, communication and expression methods, etc.) to promote the efficient teaching and learning of children's mathematics [10].

\subsection{The Content of Mathematics Course is Closely Related to Children's Real Life}

For preschool children, the most valuable course is the knowledge they can perceive, which is derived from 
practical life experience. The closer the course content is to life experience, the more it can stimulate children's interest in learning, and the best learning effect will be achieved. Social constructivism attaches importance to the relationship between life and mathematics, emphasizes the contextualization and life-orientation of children's mathematics learning content, respects children's existing knowledge and experience, advocates the gamification and operationalization of children's mathematics teaching, and pays attention to children's interest, emotional experience and interaction between teachers and children in the process of mathematics learning[11]. The UK attaches great importance to the application of mathematics in the life of preschool children, and emphasizes the development of mathematical application ability and understanding of mathematics in dealing with practical problems, cooperation and communication and other activities to form the initial basic mathematical literacy. "Children learn to use mathematical language to describe the shapes and features of objects in their lives when discussing and comparing properties such as size, volume and distance [12]."

\subsection{Pay attention to the Math Experience of Preschool Children and Promote Math Learning in "Games"}

The British preschool curriculum standards require teachers to teach children to recognize numbers, graphics and symbols. For example, they should use graphics to draw the symbolic entities of the kindergarten and arrange them in order to develop sequencing, counting and sense of position. Children are encouraged to compare the size of objects by eye measurement, ruler, palm, etc. It can also simulate trading games with children to help them master the application of mathematical knowledge in daily life [13]. Britain attaches great importance to the game for children's learning and development of important value, because it has the characteristics of pleasure and challenge, the game is defined as "well-planned play", and use it as the main way of children in the preschool stage of learning, through to stimulate children's mathematics learning to solve problems, improve the mathematical application ability [14]. This selfexploring learning method gives children more opportunities to try, explore and imagine, enabling them to perceive the quantitative relations between objects in their hands.

\subsection{Education Means Modernization}

Because children's characteristics are specific image thinking and short attention time, the use of multimedia teaching means to create new kindergarten environment, stimulate young children's learning desire and interest. Through the vivid images of the clear text and beautiful language, it can make children relaxed and happy learning, so as to achieve a shift from the traditional single knowledge education to pay attention to children's interest, experience, needs, emotion and so on with multidimensional training of quality education. In order to improve the effectiveness of education, British kindergartens pay great attention to the use of information technology in the curriculum, and strive to achieve the combination of pictures and texts. Every class is equipped with a computer, which can be used by children arbitrarily, and they can recognize Numbers and geometric figures [15]. To ensure the development of children's math knowledge and skills, teachers need to receive relevant computer education training and master its teaching technology, so as to effectively provide children with vivid, intuitive and convenient math education materials [16].

\section{ENLIGHTENMENT TO CHINESE KINDERGARTEN MATHEMATICS EDUCATION}

Some studies have pointed out that the teaching of mathematics education in Chinese kindergartens is dominated by the traditional education model, and there is a deviation in teaching children's inaccurate mathematics knowledge. The teaching process does not pay attention to the cultivation of children's thinking ability. What's more, the teaching means and methods are single, and there are problems such as the tendency of primary school [17]. Drawing on the curriculum setting and features of British preschool mathematics education, China's kindergarten mathematics education should be reformed from the following aspects.

\subsection{Highlights the Cultivation of Preschool Children's Ability to Apply Mathematics}

Kindergarten mathematics education should follow children's age characteristics, conform to children's cognitive development level, and provide children with acceptable and appropriate mathematics education content. To guide preschool children to apply the constructed mathematical knowledge and methods to solve some simple problems in life and games, and to promote the acquisition of specific mathematical knowledge and skills in problem solving [18]. For example, teach children to learn simple methods of comparison, ordering and measurement in activities. Learn to study and think, understand how to use the senses to perceive the quantitative, spatial and temporal relations of objective things in an orderly way, integrate into mathematical activities, and experience the fun and significance of mathematics. In conclusion, China's kindergarten mathematics education should follow the new concept and principle of basic education curriculum reform, emphasizing helping children understand basic mathematics concepts in the process of solving practical 
problems, cultivating their exploration ability and developing their cognitive ability.

\subsection{The Content of Mathematics Education Should Start from the Life Experience of Children}

Dewey pointed out that the learning of knowledge should be integrated into children's own experience and activities. "Kindergarten Education Guidelines" advocates that children should apply mathematics, understand mathematics and learn mathematics in life and games and in the process of solving problems. Mathematical education and children's life is closely linked, which is helpful for the application of preschool children's mathematical consciousness, to make them truly realized mathematics and the relationship between nature and human society understand the value of mathematics, to improve the understanding of mathematics, so as to construct the preschool children's continuous and complete system of mathematics knowledge, promote the development of their cognitive structure. The operation of life scene and game is an ideal way to acquire the knowledge of preschool mathematical logic [19]. The close connection between kindergarten mathematics activities and actual life will make children perceive the practical use of mathematics in life, make them pay more attention to and discover everything related to mathematics in the surrounding environment, and trigger active exploration of mathematics activities. For this, for preschool mathematics education, teachers should take a day in your life education opportunity to enrich young children's mathematical experience, such as "mathematics in life", "food shelf life" and other activities, let children feel the magic of mathematics, in the life the source without mathematics, so as to construct their relevant mathematical experience, in circumstances of life to promote the development of children's mathematical cognition ability.

\subsection{Expand a Variety of Mathematical Education Forms and Methods}

Mathematics is a complete network hierarchy built by concepts and relationships. In practice, mathematics will become creative activity content [18]. The results of the education effectiveness study and the preschool effective teaching study in the UK show that the preschool institutions that maintain a balance between the activities initiated by children and the activities initiated by teachers are more effective in teaching [20]. It is not the only form and method of mathematical education to conduct confirmatory operations and questions in collective teaching. Children should be allowed to carry out independent inquiry and discovery learning on the basis of existing knowledge and experience. "Kindergarten Education Guidelines" proposed "education in the game", properly by using game method, operation and combined with multimedia and other advanced means of teaching, introduce the mathematical education in the teaching activities such as art, music, children's songs, not only can arouse children's interest in learning, also can achieve twice the result with half the effort [21].

In short, in the future education practice, teachers have to implement the " 3 to 6 years old children's learning and development guide" and "kindergarten education guidelines" of the specific requirements. The real meaning of clear early mathematics education and their children, the value of existence, the understanding of mathematics education content system, the grasping of the key experience required for all ages children to study mathematics, to explore the kindergarten curriculum pattern. It can be integrated mathematics education with life or other areas, so as to prevent weakening mathematics curriculum.

\section{CONCLUSION}

Based on the historical review of the development of preschool mathematics education in the UK, this study analyzes the British preschool mathematics curriculum standards in terms of education policy, curriculum objectives and content framework, and draws the characteristics of the preschool mathematics curriculum in the UK. Reflected on the preschool mathematics curriculum development in China, it can put forward some enlightenment to the establishment of kindergarten mathematics curriculum standards in China. The UK's complete and mature curriculum standards system has been basically established. The spirit of openness, meticulousness, rigor and flexibility in the development of curriculum standards is also worth learning. Of course, we must also consider the way and content of reference in light of China's specific conditions, which is crucial for improving the standards of kindergarten curriculum in China.

\section{REFERENCES}

[1] The Central People's Government of the People's Republic of China. Outline of the National Medium-and Long-term Plan for Education Reform and Development (20102020).http://www.gov.cn/jrzg/201303/01/content_1667143. htm.

[2] X. Zhang.Research on the Curriculum Standards of British Preschool Mathematics. Kunming: Yunnan Normal University, 2012.

[3] Curriculum Guidance for the Foundation Stage [EB/OL].http: //ww.smart teachers.co.uk.

[4] L. Yan.Introduction of Basic Stage curriculum reform in wales. Contemporary Preschool 
Education,No.6,2007,

46.DOI:10.13627/j.cnki.cdjy.2015.12.027

pp.45-

[5] Department for Education.Statutory Framework for the Early Years Foudation Stage 2012 [EB/OL].http://www.education.gov.uk/publications /standards/AllPublications/Pagel/DFE-000232012.2012-3-30.

[6] T. Wang.A Comparative Study on The Education Content of Pre-school Mathematics in China, Britain and the United States -- Based on The Analysis of Curriculum Standards in Three Countries.Early Education,No.11,2015, pp.15-18.

[7] Department for Education and Employment. The National Numeracy Strategy: Frameworkfor Teaching Mathematics from Reception to Year 6. London: DF EE, 1999.

[8] Q. Kong.Several Trends of International Mathematics Curriculum Reform in Recent Years [J].Foreign Education Information, No.6, 2006, pp. 23-26.

[9] Welsh Assembly Government: Foundation Phase Guidance Material—-Mathematical Development (Initial Draft).http://www.gysgu.cymru.gov. UK.

[10] N. Cao.Preschool comparative education.Shanghai: East China Normal University Press, 2009.

[11] X. Mou.Study on the Implementation of Mathem actics Education curriculum in Kindergarten. Yantai: Ludong University, 2012.

[12] BEAM Response to Revised ELGs.http://www. beam.co.uk/discussionpapers.php,2012-03-05.
[13] B. Liang.On British Preschool Education Curriculum Provision.Studies in Preschool Education,No.7,2015, pp.6163.DOI:10.13861/j.cnki.sec e.2015.07.010

[14] M. Hodge.Curriculum Guidance for the Foundation Stage.London: Licensing Agency, 2000.

[15] H. Li, S. Chen.The curriculum Setting and its Development Trend in British Kindergartens.Studies In Foreign Education,No.9,2012, pp.9-16.

[16] C. Liu.Preschool Comparative Education.Beiji-ng: Science Press, 2007.

[17] L. Zhang.Thinking about The Existing Problems in Kindergarten Mathematics Education. Studies in Preschool Education, No.2, 2000, pp.36-37. DOI:10.13861/j.cnki.sece.2000.02.014

[18] D. Shi, X. Zhang.The Emphasis on Mathematics Application: The Characteristics of Preschool Mathematics Education in the United Kingdom and its Inspiration.Studies In Foreign Education, No.11, 2012, pp.36-41.

[19] Y. Zhao.Mathematics Educational Predicament and Countermeasure of Kindergarten.Journal of Hangzhou Teachers College (Nature Science Edition), No.5, 2007, pp.232-235.

[20] I. Siraji-Blatchford,K. Sylva,S. Muttock. Researching Effective Pedagogy in the Early Years.Lodon: Department for Education, 2002.

[21] J. Lin.Investigation Report on Children's Mathematics Entrance Preparation.Studies in Preschool Education,No.2,2000, 33.DOI:10.13861/j.cnki.sece.2000.02.012 pp.32- 